\title{
Mass-redistribution-induced crustal deformation of global satellite laser ranging stations due to non-tidal ocean and land water circulation
}

\author{
Hiroshi Takiguchi ${ }^{1}$, Toshimichi Otsubo ${ }^{2}$, and Yoichi Fukuda ${ }^{1}$ \\ ${ }^{1}$ Department of Geophysics, Graduate School of Science, Kyoto University, Kitashirakawa Oiwake-cho, Sakyo-ku, Kyoto 606-8502, Japan \\ ${ }^{2}$ National Institute of Information and Communications Technology, 893-1 Hirai, Kashima, Ibaraki 314-8501, Japan
}

(Received October 24, 2005; Revised February 3, 2006; Accepted February 6, 2006; Online published February 17, 2006)

\begin{abstract}
The effect of the non-tidal ocean load (NTOL) and the continental water load (CWL) on crustal deformation are calculated for global satellite laser ranging (SLR) stations and on $4^{\circ} \times 4^{\circ}$ grids (only over the land). For the regions most severely affected, the peak-to-peak displacements due to the NTOL are found to be as large as 3 $\mathrm{mm}$ for the horizontal components and $10 \mathrm{~mm}$ for the vertical component. The peak-to-peak displacements due to the CWL reach $3 \mathrm{~mm}$ for the horizontal components and $15 \mathrm{~mm}$ for the vertical component. We apply the time series of NTOL and CWL to precise SLR analysis. The LAGEOS orbit analysis reveals that the Estimating the Circulation and Climate of the Ocean (ECCO) model makes the root mean square (RMS) of the range residual $0.2 \%$ smaller, and that the CWL makes it $0.8 \%$ smaller, compared with the case where loading displacement is neglected. On the other hand, with the NTOL derived from Topex/Poseidon altimetry data, the SLR orbit fit is not improved.
\end{abstract}

Key words: Satellite laser ranging, non-tidal ocean load, continental water load, crustal deformation, Topex/Poseidon, ECCO.

\section{Introduction}

The atmosphere and water mass distribution over the Earth's surface is constantly changing. These mass changes affect the Earth's gravitational field and the position of the geocenter, etc. Because the Earth's crust responds elastically to surface loads on short timescales mostly at diurnal and semidiurnal frequencies, mass redistribution also produces elastic deformations of the Earth itself. The recent development of space geodesy technology has made it possible to observe these displacements. If one incorporates the geodesy data, more accurate studies of crustal deformation can be made.

The main sources of mass change on the Earth's surface are the atmosphere, oceans and continental water. The atmospheric loading displacements have been firstly observed by very long baseline interferometry (VLBI) and global positioning system (GPS) techniques (van Dam and Herring, 1994; van Dam et al., 1994). Moreover, some studies have compared VLBI and GPS observations with loading displacements estimated using surface pressure or sea level data (Mangiarotti et al., 2001; van Dam et al., 1998, 2001; Dong et al., 2002; Munekane and Matsuzaka, 2004).

Some researchers routinely calculate the load displacements due to atmospheric loading (AL) and upload the results to web sites (The Special Bureau for Loading of the Global Geophysical Fluid Center, Petrov and Boy, 2004). On the other hand, in contrast to the AL, data with sufficiently high space-time resolution have been lacking for the

Copy right(c) The Society of Geomagnetism and Earth, Planetary and Space Sciences (SGEPSS); The Seismological Society of Japan; The Volcanological Society of Japan; The Geodetic Society of Japan; The Japanese Society for Planetary Sciences; TERRAPUB non-tidal ocean load (NTOL) and continental water load (CWL). There have therefore been few studies of the effects of NTOL and CWL. In this study, we calculate the influence of the NTOL and the CWL using meteorological data that have recently become available.

In this work, we use the time series of NTOL and CWL for precise satellite laser ranging (SLR) analysis. While the SLR technique has disadvantages in that the observations are influenced by the weather and the time resolution is relatively poor, it has important advantages in that the station-satellite range can be directly measured and the tropospheric delay can be accurately modeled due to the optical nature. This results in accurate determination of the vertical component which is the main component of loading displacement.

\section{Calculation of Surface Loads \\ 2.1 Methodology}

The deformation of the Earth's surface produced by changes in the several surface mass sources can be estimated from knowledge of the data at the surface by convolving data with Green's functions (Farrell, 1972). The elastic deformation $\mathrm{L}$ is given by a global integral:

$$
L\left(\theta^{\prime}, \lambda^{\prime}\right)=\rho \iint H(\theta, \lambda) G_{L}(\phi) T(\alpha) d S
$$

where $\rho$ is the mean density of sea water or soil moisture, $H$ is the variation of the source data (soil moisture anomaly etc.), $G_{L}$ is the mass-loading Green's function of displacements (Farrell, 1972), and $T$ is a combination of the trigonometric functions of azimuth $(\alpha) . G_{L}$ is a function of the angular distance $(\phi)$ between the estimation point with 


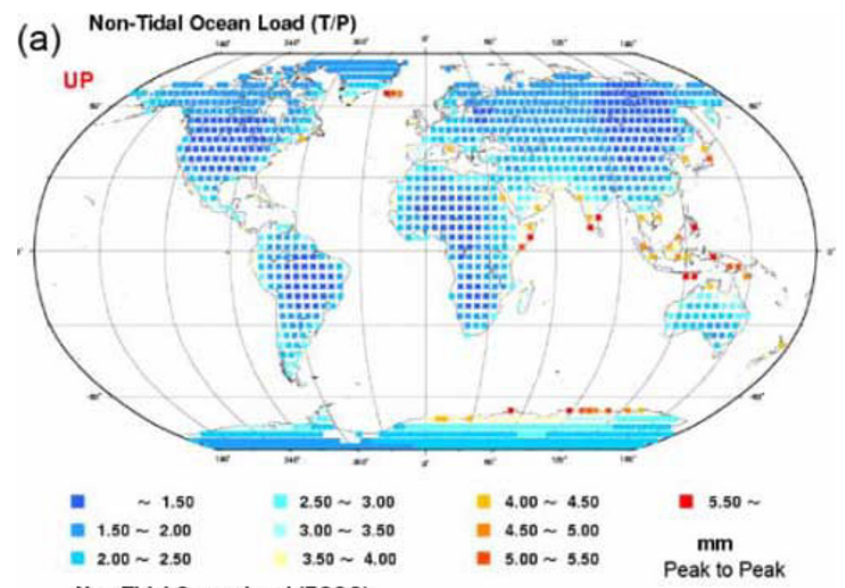

(b)
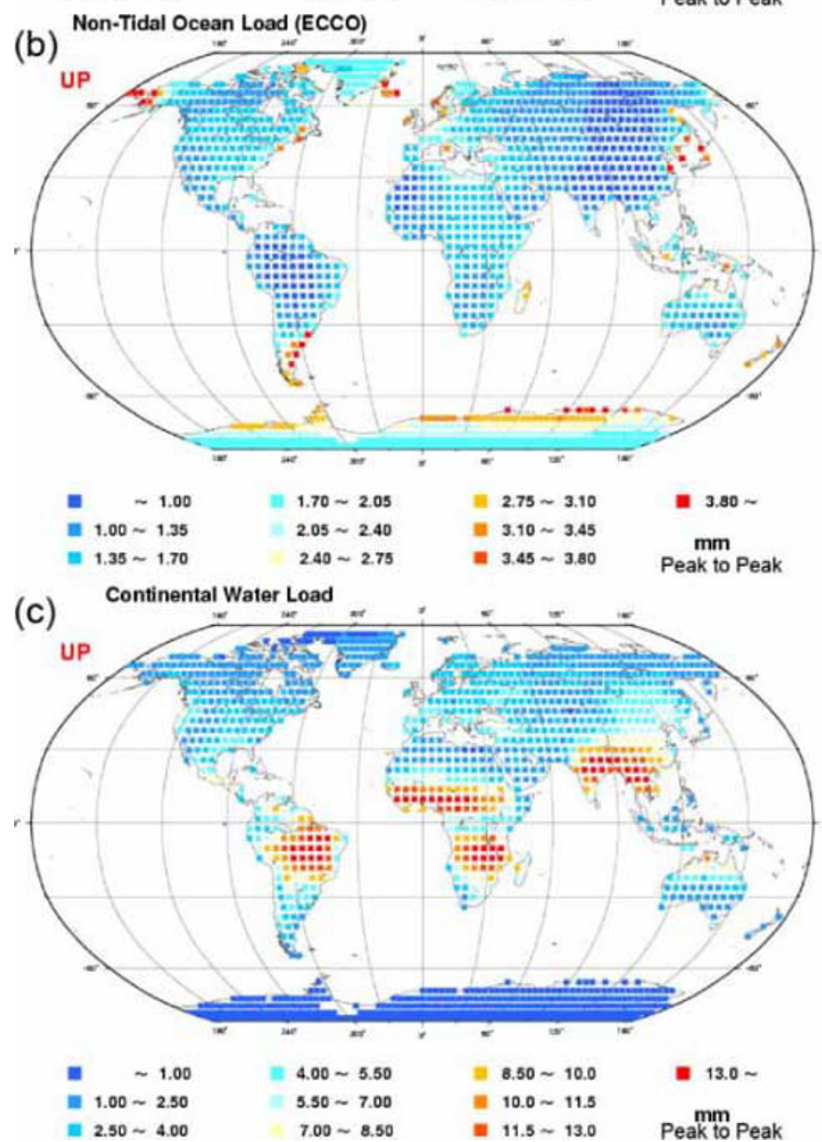

Fig. 1. The fluctuations (peak-to-peak) in the distribution of vertical component at the $4^{\circ} \times 4^{\circ}$ grid points (only over the land) due to T/P-NTOL, ECCO-NTOL and CWL models.

coordinates (colatitude, longitude) $=\left(\theta^{\prime}, \lambda^{\prime}\right)$ and the loading point $(\theta, \lambda)$. For example, the Green's function for radial displacement is expressed as

$$
G_{L}^{R D}(\phi)=\frac{R}{M_{e}} \sum_{n=0}^{\infty} h_{n}^{\prime} P_{n}(\cos \phi)
$$

where $M_{e}$ and $R$ are the mass and radius of the Earth, $h^{\prime}$ is the loading Love number, and $P_{n}$ is the Legendre function of degree $n$ (Matsumoto et al., 2001).

In this study we used GOTIC2 (Global Oceanic Tidal Correction version 2, Matsumoto et al., 2001) subroutine programs and a high-resolution land-sea database (global spatial resolution is $5^{\prime} \times 5^{\prime}$ grids).

\subsection{Data}

To calculate the loading displacements, we need input data for the global mass distribution. In this study, we used the altimeter data from Topex/Poseidon (T/P) and the ocean bottom pressure data from Estimating the Circulation and Climate of the Ocean (ECCO) for the NTOL, and the soil moisture data by Fan and van den Dool (2004) for the CWL. The ECCO model that we used, employs assimilation method that is called a partitioned Kalman filter and a partitioned RTS smoother (PKF and PS) (Fukumori, 2002). By assimilating temporal anomalies of satellite sea surface height $(\mathrm{T} / \mathrm{P})$ and those of temperature, the PKF and PS estimate large-scale adiabatic adjustments of the model state and associated corrections in wind forcing.

The T/P altimetry data was the sea level data from the World Ocean Circulation Experiment Satellite Data version $3.0\left(1.0^{\circ} \times 1.0^{\circ}\right.$ grid with 5 days resolution from $1997-$ 2001). Sea level data include steric height changes caused by temperature and salinity (Gill and Niiler, 1973) that do not induce mass changes. To correct for these factors, we assumed a linear relationship $\left(6 \mathrm{~mm} /{ }^{\circ} \mathrm{C}\right)$ between the sea surface temperature (SST) and steric height (Sato et al., 2001) and calculated correction factors using SST data from the 5-channel Advanced Very High Resolution Radiometers (AVHRR). We didn't consider the salinity effects of the steric height changes, because these effects are smaller than the temperature effects and the salinity data coverage is sparse in some regions. It will be considered in a future paper. The ocean bottom pressure data from the ECCO model are available twice daily (00 and 12 UTC) on a $1^{\circ} \times 1^{\circ}$ grid (Marshall et al., 1997a, b; Köhl et al., 2002). The soil moisture data from Fan and van den Dool 2004 were derived from the land model, i.e. a one-layer "bucket" water balance model. The inputs to this model are the Climate Prediction Center monthly global precipitation over land, which uses over 17,000 gauges worldwide, and the monthly global temperature from global reanalysis. These data are available on a $0.5^{\circ} \times 0.5^{\circ}$ grid with data for every month from 1948 to the present. (http://www.cpc.ncep.noaa.gov/soilmst/leaky_glb.htm)

In this study, we used the NTOL using T/P data (hereafter referred to as T/P-NTOL) for the period of 1997-2001, the NTOL using the ECCO model (ECCO-NTOL) for 19971999, and the CWL for 1997-2001.

\subsection{Characteristics of surface loads}

We calculated loading displacements at each of the global SLR stations and on $4^{\circ} \times 4^{\circ}$ grids (only over the land). The SLR stations belong to the International Laser Ranging Service (ILRS) and that total number is 54 stations. From these results, we constructed a database for the three types of loads (T/P-NTOL, ECCO-NTOL and CWL) as a function of time at every station. In Fig. 1 we show the distributions of the respective displacements calculated from the T/P-NTOL, the ECCO-NTOL and the CWL. The figure shows the fluctuations (peak-to-peak) in the distribution of vertical component at the calculated points.

Near the equator, the displacements due to T/P-NTOL were large at islands and the continental coasts (Fig. 1(a)). Also, the displacements were large for the Pacific side of the Japanese archipelago. In the most severely affected 
Table 1. The overall result of the precise SLR analysis. In the first column, the annual weighted RMS results of the (1) baseline case are listed. For the second to fourth column, the weighted RMS and the improvement percentage from the baseline case are shown for the case (2) to (4).

\begin{tabular}{|c|c|c|c|c|c|c|c|}
\hline & $\begin{array}{c}\text { (1) none } \\
\text { rms } \\
(\mathrm{mm})\end{array}$ & $\begin{array}{l}(2) \\
\mathrm{rms} \\
(\mathrm{mm})\end{array}$ & $\begin{array}{l}\text { JTOL } \\
(\%)\end{array}$ & $\begin{array}{l}\text { (3) E } \\
\text { rms } \\
(\mathrm{mm})\end{array}$ & $\begin{array}{r}\text { NTOL } \\
(\%)\end{array}$ & $\begin{array}{l}\mathrm{rms}^{(4} \\
(\mathrm{mm})\end{array}$ & $(\%)$ \\
\hline 199701 & 9.535 & 9.534 & 0.010 & 9.519 & 0.168 & 9.470 & 0.682 \\
\hline 199801 & 9.473 & 9.477 & -0.042 & 9.445 & 0.296 & 9.323 & 1.583 \\
\hline 199901 & 9.205 & 9.209 & -0.043 & 9.206 & -0.011 & 9.136 & 0.750 \\
\hline 200001 & 9.738 & 9.737 & 0.010 & & & 9.679 & 0.606 \\
\hline 200101 & 9.249 & 9.279 & -0.324 & & & 9.214 & 0.378 \\
\hline mean & 9.440 & 9.447 & -0.078 & 9.390 & 0.151 & 9.364 & 0.800 \\
\hline
\end{tabular}

geographic regions, the displacements were found to be as large as $2 \mathrm{~mm}$ for the horizontal components and $6 \mathrm{~mm}$ for the vertical component. On the other hand, in regions such as the continental interior, the deformation values due to T/P-NTOL were less than $1 \mathrm{~mm}$.

On the other hand, although a rough tendency of the ECCO-NTOL looks like T/P-NTOL, the displacement of the region where it faced the southern part of the South America, islands in low latitudes, and the Sea of Japan is different. In the most severely affected geographic regions, the displacements were found to be as large as $3 \mathrm{~mm}$ for the horizontal components and $10 \mathrm{~mm}$ for the vertical component. Displacement is smaller than T/P-NTOL when averaging (Fig. 1(b)).

With regard to the CWL, the displacements were the largest for Amazon, the region in the south from Sahara desert and India-Southeast Asia area (Fig. 1(c)). In such cases, displacements exceeding $3 \mathrm{~mm}$ for the horizontal components and $15 \mathrm{~mm}$ for the vertical component were observed. However, for high-latitude regions, archipelagos like Japan, and desert zones the modeled deformations due to the CWL were less significant.

\section{Analysis of SLR Data}

\subsection{Procedure}

For analysis of the SLR data we used the 'concerto' program (version 4) developed by the National Institute of Information and Communications Technology (NICT). We added additional functions to the program to include the effects of 3D NTOL and CWL fluctuations. Linear interpolation is applied to the evenly spaced time series of loading displacement so that the displacement at an observation epoch is obtained. Details regarding the basic structure and the model in the software were given by Otsubo 2005.

For the period of 1997-2001, yearly analyses were carried out for the following four cases: (1) baseline; without any of these loading effects, (2) baseline plus T/P-NTOL, (3) baseline plus ECCO-NTOL (1997-1999), and (4) baseline plus CWL. We used the normal point data of two satellites, LAGEOS-1 and LAGEOS-2, whose orbital parameters (six elements, along-track constant acceleration and along-track once-per-rev acceleration) were estimated every six days. The coordinates of all SLR stations are estimated every year. In addition, the range biases were also estimated every year to absorb the ambiguity of centerof-mass correction of LAGEOS satellites (Otsubo and Appleby, 2003).

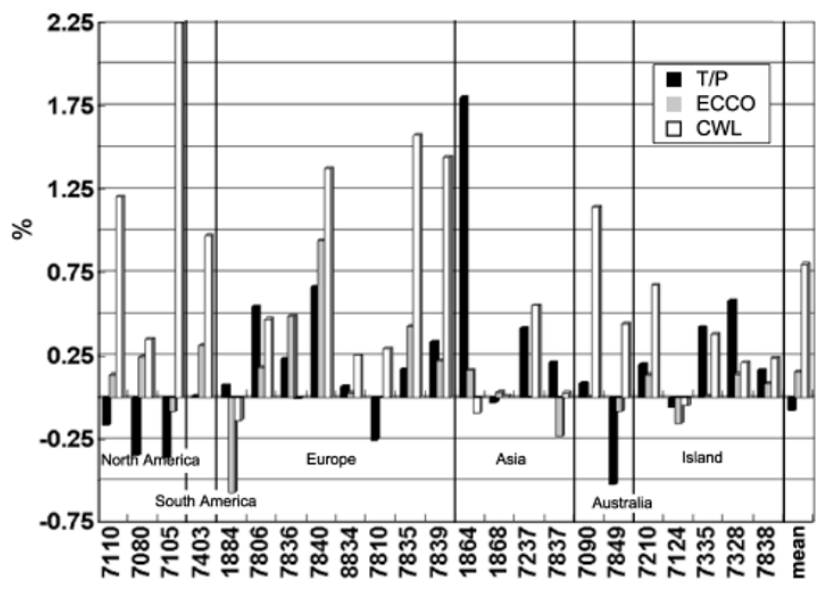

Fig. 2. The percent improvement in the station-by-station RMS values of the precise SLR analysis for major stations. The non-tidal ocean load from Topex/Poseidon indicated as black bars and ECCO model indicated as gray bars, and the continental water load indicated as white bars.

We look into the overall post-fit weighted residual root mean square (RMS) of SLR normal point data. We also look into RMS of each station. Since a good model should fit well the observation, the smaller RMS will indicate the usefulness of a model.

\subsection{Results}

Table 1 shows the results of the analysis. In the first column, the annual weighted RMS results of the (1) baseline case are listed. For the second to fourth column, the weighted RMS and the improvement percentage from the baseline case are shown for the case (2) to (4). With regard to the case (2) T/P-NTOL, the RMS increased on average from the baseline. Considering the fact that the RMS increased in the period of 1998 and 1999, the influence of El Nino and La Nina might not be able to be removed from the altimeter data completely. Moreover, the assumption of 6 $\mathrm{mm} /{ }^{\circ} \mathrm{C}$ might be unreasonable at all over the world. With regard for the ECCO-NTOL and the CWL, the weighted RMS values almost always get smaller. On average, the weighted RMS decreased $0.2 \%$ for mass-loading displacement corrections using the ECCO-NTOL, and $0.8 \%$ for CWL.

In Fig. 2 we show the percent improvement in the stationby-station RMS values. A large reduction was observed for North American, South American, Europe and Australia stations when using CWL. Compared to the ECCO-NTOL 
case, the $\mathrm{T} / \mathrm{P}$ results behave rather poorly in the island in the Pacific Ocean and the point in the vicinity of North America and the Mediterranean. It is thought that this is a problem of the observation accuracy in the inland sea of the T/P and the problem of the correction of above-mentioned steric height or time resolution of the raw data.

\section{Conclusion}

We calculated the effects of the NTOL and the CWL on crustal deformation at global SLR stations and on $4^{\circ} \times 4^{\circ}$ grids. In the geographic regions most severely affected, the displacements due to NTOL were found to be as large as $2 \mathrm{~mm}$ for the horizontal components and 6-10 $\mathrm{mm}$ for the vertical component. The displacements due to CWL were up to $3 \mathrm{~mm}$ for the horizontal components and up to $15 \mathrm{~mm}$ for the vertical component.

Furthermore, a precise analysis of SLR has been made using the NTOL and CWL data. The post-fit weighted RMS improved by $0.2 \%$ with the ECCO-NTOL and by $0.8 \%$ with the CWL, compared to the cases where mass loading effects were ignored.

In the present work, we have analyzed the effects of two mass loading factors (NTOL and CWL) considered separately. If more loading factors are analyzed together the improvement will be additive. As source data with improved space-time resolution becomes available in the future, the precision of space geodetic analysis is expected to improve. Although the present study focused on SLR data, the model developed in this work can be applied to VLBI and GPS data.

Acknowledgments. We kindly acknowledge WOCE, NOAA, ECCO, and CPC for providing data used in our analysis (web addresses given below). We used the subroutines of GOTIC2 to calculate the load displacements and concerto for the SLR analysis. Dr. Toshihiro Kubo-oka and Mr. Tadahiro Gotoh supported the development of the concerto software. The SLR observations were provided by the International Laser Ranging Service. The public domain software Generic Mapping Tools (GMT) by Wessel and Smith was used to prepare the figures in this paper. The comments by EPS editor and two anonymous reviewers are quite helpful on improving the manuscript. [WOCE (http://podaac.jpl.nasa.gov/woce/), NOAA (http://www.cdc.noaa.gov/), ECCO (http://www.ecco-group.org/), CPC (http://www.cpc.ncep.noaa.gov/soilmst/leaky_glb.htm)]

\section{References}

Dong, D., P. Fang, Y. Bock, M. K. Cheng, and S. Miyazaki, Anatomy of apparent seasonal variations from GPS-derived site position time series, J. Geophys. Res., 107(B4), 2075, 2002.

Fan, Y. and H. van den Dool, Climate Prediction Center global monthly soil moisture data set at $0.5^{\circ}$ resolution for 1948 to present, J. Geophys. Res., 109, D10102, 2004.

Farrell, W. E., Deformation of the Earth by surface loads, Rev. Geophys. and Spac. Phys., 10(3), 751-797, 1972.

Fukumori, I., A partitioned Kalman filter and smoother, Mon. Weather Rev., 130, 1370-1383, 2002.

Gill, A. E. and P. Niiler, The theory of seasonal variability in the ocean, Deep Sea Res. Oceanogr. Abstr., 141, 141-177, 1973.

Köhl, A., D. Stammer, B. Cornuelle, E. Remy, Y. Lu, P. Heimbach, and C. Wunsch, The Global $1^{\circ}$ WOCE Synthesis: 1992-2001, ECCO Rep. Ser., Rep. No. 20. Estimating the Circ. and Clim. of the Ocean, Jet Propul. Lab., Pasadena, Calif, 2002.

Mangiarotti, S., A. Cazenave, L. Soudarin, and J. F. Cretaux, Annual vertical crustal motions predicted from surface mass redistribution and observed by space geodesy, J. Geophys. Res., 106, 4277-4292, 2001.

Marshall, J., C. Hill, L. Perelman, and A. Adcroft, Hydrostatic, quasihydrostatic and nonhydrostatic ocean modeling, J. Geophys. Res., 102, 5733-5752, 1997a.

Marshall, J., A. Adcroft, C. Hill, L. Perelman, and C. Heisey, A finitevolume, incompressible Navier-Stokes model for studies of the ocean on parallel computers, J. Geophys. Res., 102, 5753-5766, $1997 \mathrm{~b}$.

Matsumoto, K., T. Sato, T. Takanezawa, and M. Ooe, GOTIC2: A program for computation of oceanic tidal loading effect, J. Geod. Soc. Japan, 47(1), 243-248, 2001.

Munekane, H. and S. Matsuzaka, Nontidal ocean mass loading detected by GPS observations in the tropical Pacific region, Geophys. Res. Let., 31, L08602, 2004.

Otsubo, T., Improving the analysis precision of satellite laser ranging data from centimeter to millimeter range, J. Geod. Soc. Japan, 51(1), 1-16, 2005.

Otsubo, T. and G. M. Appleby, System-dependent center-of-mass correction for spherical geodetic satellites, J. Geophys. Res., 108(B4), 2201, 2003.

Petrov, L. and J.-P. Boy, Study of the atmospheric pressure loading signal in very long baseline interferometry observations, J. Geophys. Res., 109, B03405, 2004.

Sato, T., Y. Fukuda, Y. Aoyama et al., On the observed annual gravity variation and the effect of sea surface height variations, Phys. Earth Planet. Inter., 123, 45-63, 2001.

van Dam, T. M. and T. A. Herring, Detection of atmospheric pressure loading using very long baseline interferometry measurements, J. Geophys. Res., 99, 4505-4518, 1994.

van Dam, T. M. and J. Wahr, Modeling environment loading effects: A review, Phys. Chem. Earth, 23(9-10), 1077-1087, 1998.

van Dam, T. M., G. Blewitt, and M. B. Heflin, Atmospheric pressure loading effects on Global Positioning System coordinate determinations, $J$. Geophys. Res., 99, 23,939-23,950, 1994.

van Dam, T., J. Wahr, P. C. D. Milly, A. B. Shmakin, G. Blewitt, D. Lavallee, and K. M. Larson, Crustal displacements due to continental water loading, Geophys. Res. Let., 28(4), 651-654, 2001.

H. Takiguchi (e-mail: taki@kugi.kyoto-u.ac.jp), T. Otsubo, and Y. 